\title{
An Effective Allocation Model of Computer Teaching Management Resources Based on Particle Swarm Optimization
}

\author{
https://doi.org/10.3991/ijet.v14i18.11189 \\ Xiang Yang \\ Nanjing University of Finance \& Economics, Nanjing, China \\ yangxiangoeds@163.com
}

\begin{abstract}
This paper attempts to improve the resource utilization in computer teaching, striking a balance between educational resource and education development. For this purpose, the author systematically investigated the allocation of computer teaching management resources, and set up an effective allocation model of such resources based on particle swarm optimization (PSO). The research results show that the PSO-based model can coordinate the allocation of computer teaching management resources, enhance the utilization rate of teaching resources, and prevent resource waste. With the aid of the proposed model, the imbalance between different counties and districts in the number of computers and teachers was greatly improved, which contributes to the coordinated development of education in the study area. The research findings have great theoretical and social significance for the sustainable development of education and the improvement of the education system.
\end{abstract}

Keywords-Computer teaching management, resource allocation model, particle swarm optimization (PSO), educational resources

\section{Introduction}

The educational development in schools requires the support of human and material resources, which is closely related to the balanced and effective allocation of resources between regions or schools [1-3]. Scientific research and practical experience have shown that educational resources are the basis for educational activities at all levels of school and for the development of education in the country [4-6]. The low utilization rate of educational resources causes the waste of resources, and also the shortage of educational resources, hindering the development of education [7-8]. In recent years, despite the rapid development of China's social economy, the highquality talents needed for social development are still in short supply. Relevant policies have promoted the expansion of education scale and education demand, but the existing educational resources still cannot match the educational needs of all levels, which hinders the cultivation of high-level talents or high-tech talents to a certain 
extent [9-10]. Therefore, it can minimize the waste of educational resources to improve the effective utilization of educational resources.

Following the development of information technology and the rapid advancement of science and technology, the study of computer information technology has become crucial in lower education, secondary education and higher education [11-12]. The rational allocation of computer teaching management resources includes the coordination, distribution, optimization and reorganization of professional teachers and computer accessories, and the in-depth development of educational management resources to improve the utilization of such resources [13-14]. Information technology is the foundation of all kinds of technology and economic development in the world today. The cultivation of computer talents is the irreversible trend of the times, so, for the schools at all levels, intensifying computer education and effectively allocating the computer education management resources are extremely important [15-16]. In short, in order to meet the needs of cultivating all kinds of professional and technical personnel with limited educational resources such as computer resources and teacher resources, it is necessary to minimize the waste of educational resources and resource consumption, balance the distribution of educational resources and conduct effective management.

In view of the above problems, this paper first conducts survey and statistical analysis for the educational resources such as computer teaching resources and teacher allocation in one school of certain region, and then establishes an effective allocation model of computer teaching management resources based on PSO and related mathematical analysis theory. In addition, the computer teaching management resources in this region were redistributed to verify the applicability and accuracy of the model. This provides theoretical support for improving the utilization of educational resources and promoting the development of education.

\section{$2 \quad$ Related Theory about PSO Theory}

\subsection{Development of PSO}

The PSO algorithm was first proposed by foreign scholar Kennedy J \& Eberhart R.C in 1995. It is a random optimization algorithm based on population. The PSO is inspired by the foraging behaviour of the colonial animals, that is, the individual shares the food information to the group through individual search, and then the group finds the food at the fastest speed [17].

During the foraging process of the bird flock, Kennedy observed that the birds are not able to perceive the movement of the entire flock, but instead change their position according to the flying position and direction of the birds nearby. Therefore, scientists have developed PSO into two modes: global best and local best. In the mode of global best, affected by the entire particle swarm, each particle aims to trace its extremum and the global extremum; in the mode of local best, the particle is affected by its own consciousness and the surrounding particles in motion, but not subject to 
the global particles, so it only pursues the extremum of itself and neighbouring particles. The former converges faster.

In the early PSO model, the Boid model was designed imitating the bird flock foraging; any bird is represented by a node, and given with the initial velocity and displacement; based on the principle of "near speed matching" in the program, the speed of all nodes will tend to be similar or the same. However, in the follow-up study, it's found that the Boid model was too simple, and its calculated results deviated a lot from the real results. Thus, the random variables are added to the velocity variables, and then the optimization iteration is performed, so that a new random variable is added for each update speed, which can maximize the degree of mimicking the process of bird foraging.

In the PSO algorithm, the optimization problem is understood as: there exist a myriad of particles in a multidimensional space; each particle has a velocity variable, and its direction and displacement are changed constantly. When the algorithm is performed, all particle swarms centre around the current optimal solution for optimization. For the optimal solution in the swarm obtained by individual optimization, it's simpler than the genetic algorithm, and has fewer design parameters and is easier to implement [18-19].

\subsection{Basic steps of the PSO}

It is assumed that in the $\mathrm{k}$-dimensional space, particles with $\mathrm{m}$ target potential problem solutions form a swarm, as shown in equation (1):

$$
S=\left\{X_{1}, X_{2}, \ldots, X_{m}\right\}
$$

Among them, the variable $X_{\mathrm{m}}$ represents the position of the m-th particle in the kdimensional space. Substituting its value into the adaptive function, the fitness value of the i-th particle can be obtained. The initial velocity variable of each particle is represented by $V_{\mathrm{i}}, V_{i}=\left(v_{1}, v_{2}, \ldots, v_{i}\right), i=1,2, \ldots, m ; \mathrm{P}$ is used to record the optimal position of the particle, and $\mathrm{P}_{\mathrm{g}}$ is the optimal position of the swarm, containing location information for each particle point.

According to the principle of adhering to the optimal particle, it is easy to acquire the calculation formula for the position and velocity of the particle, which is expressed as:

$$
\begin{gathered}
V_{i}^{n+1}=\omega V_{i}^{n}+c_{1} r_{1}\left(p_{i}-X_{i}\right)+c_{2} r_{2}\left(p_{g}-X_{i}\right) \\
X_{I}^{n+1}=X_{i}^{n}+V_{i}^{n}
\end{gathered}
$$

Where, $i$ is the particle number, $n$ is the number of iterations, $c_{1}, c_{2}$ are the learning factors, $r_{1}, r_{2}$ are random numbers between $0-1$, and $\omega$ is the inertia factor. A larger value of $\omega$ is advantageous for obtaining an overall optimal solution, while a smaller value of $\omega$ can help to improve the precision of the algorithm. In order to better con- 
trol the search range and value within a reasonable range, the maximum value of $V$ and the minimum value of $X$ were specified. The standard calculation steps are given as: set parameters and initialize the population, and set the initial velocity and position of the particles; calculate the fitness value of the particle; update the position and velocity of the particle; by comparing the fitness value of the single particle with the position experienced by the particle, and the position of the particle swarm with the adaptive value of the swarm, take the current value if the comparison results are satisfactory; calculate the fitness value of the new position for the particle; update the optimal solution of the individual, and the optimal solution of the population; find the optimal solution and end the calculation, or return (3) if the optimal solution is not found.

\section{An Allocation Model of Computer Teaching Management Resource Based on Particle Swarm Optimization}

\subsection{A PSO-based allocation model of computer education resources}

According to the correlation theory of particle swarm, the flow of the PSO-based allocation model is shown in Figure 1:

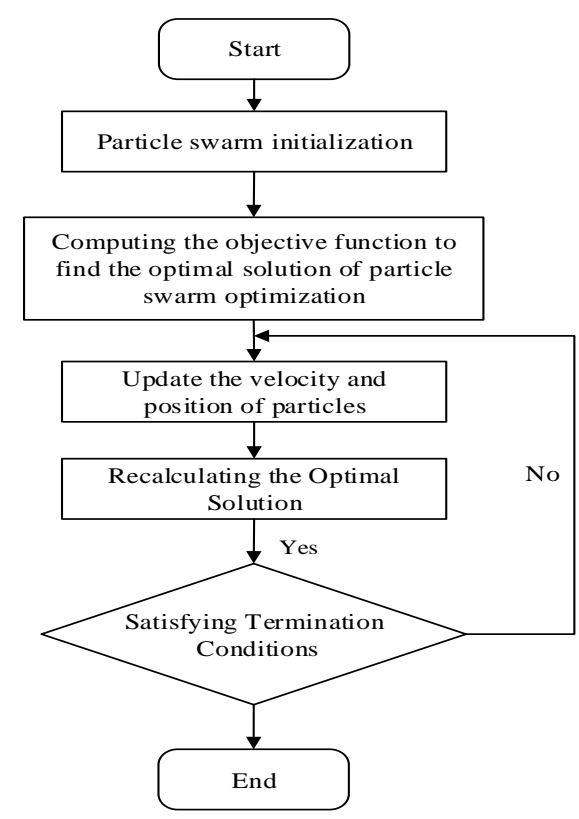

Fig. 1. Flow chart of POS allocation model

It mainly consists of four steps: particle swarm initialization, updating the position of the particles, recalculating the optimal solution, and termination by verification. 
The number of particles in the particle swarm will directly affect the optimal solution. The excessive or undersized number of particle swarm shall cause the final results to deviate in a large degree, so the number of initial particle swarm should be easily controlled between 15-30. The position of the particle is updated by updating the velocity of the particle, wherein the learning factor is 2.0 , the inertia weight is 1.5 , and the inertia weight is gradually reduced to 0.2 with the number of iterations, thereby ensuring the global searching ability of the particle swarm; the updating speed of particles is in the range of $[-1,1]$; the allocated resources vary in terms of the different number of resources, ensuring global optimization. When the particle position changes the fitness value $M$ is calculated to continuously adjust the optimal solution of the particle. The fitness $\mathrm{M}$ is calculated as:

$$
\mathrm{M}=\mathrm{M}+\left(\frac{N_{i}+n_{i}}{s_{i}}-\frac{\sum N_{i}+\sum N_{i}}{\sum s_{i}}\right)^{2}
$$

Among them, $N_{\mathrm{i}}, n_{\mathrm{i}}, s_{\mathrm{i}}$ respectively indicate the number of resources in each county and district, the number of allocable resources, and the number of students.

The initial $\mathrm{M}$ value is 0 . If the resources of the districts and counties below the average are adjusted, the resources can be balanced between the districts and counties, and the total value of the fitness shall be reduced. If the resources of the districts and counties above the average are adjusted, this will result in a larger mean square error, failing to achieve the goal of reducing the total fitness. Therefore, each time a new value is calculated, it should be compared with the previously calculated value, to take a smaller value, and then iterated to find the optimal solution. The verification terminates on the condition that there is no change in the result after multiple iterations, or the number of iterations exceeds the initial number.

\subsection{Distribution of educational resources}

The educational resources of teachers, students and computers in various counties and districts in a certain city of Shaanxi Province were collected. The specific results are shown in Table 1, where districts and counties are denoted by numbers.

Table 1. Statistics of a county in Shaanxi Province

\begin{tabular}{|c|c|c|c|c|c|}
\hline $\begin{array}{c}\text { Serial } \\
\text { number }\end{array}$ & $\begin{array}{c}\text { Number of } \\
\text { students }\end{array}$ & $\begin{array}{c}\text { Number of } \\
\text { Teachers }\end{array}$ & $\begin{array}{c}\text { Student to } \\
\text { Teacher Ratio }\end{array}$ & $\begin{array}{c}\text { Number of com- } \\
\text { puters }\end{array}$ & $\begin{array}{c}\text { Number of computers } \\
\text { per capita }\end{array}$ \\
\hline 1 & 18231 & 2489 & 7.325 & 7891 & 0.433 \\
\hline 2 & 23012 & 2602 & 8.844 & 15203 & 0.661 \\
\hline 3 & 6483 & 1223 & 5.301 & 5821 & 0.898 \\
\hline 4 & 8827 & 2134 & 4.136 & 6321 & 0.716 \\
\hline 5 & 12057 & 1809 & 6.665 & 8012 & 0.665 \\
\hline 6 & 16290 & 1608 & 10.131 & 5022 & 0.308 \\
\hline 7 & 13921 & 2404 & 5.791 & 11456 & 0.823 \\
\hline 8 & 15029 & 2315 & 6.492 & 9021 & 0.600 \\
\hline 9 & 13892 & 1208 & 11.500 & 10023 & 0.721 \\
\hline 10 & 15932 & 2107 & 7.561 & 7405 & 0.465 \\
\hline
\end{tabular}


The allocation of educational resources in various regions were taken into full consideration in this paper, with the purpose of narrowing the gap between educational resources in counties and cities. The gap between resource allocation was taken as the measurement standard. The higher ratio of students to teachers means more students taught by each teacher, so with the lower student-teacher ratio, the teacher can put more energy on each student. It's better to have more computers, that is, if the students are allocated with more educational resources, the learning effect shall be better. On the whole, there is a big gap in the number of students and the number of computers per capita between counties and districts, indicating a significant imbalance of educational resources in the region.

In order to achieve the balance and optimal distribution of educational resources, the most ideal state is that the number of students and the number of computers per capita is equal in all counties and cities. Thus, it is necessary to adjust the ratio of students to teachers, increase the number of computers per capita, thereby striking a balance in educational resources between the regions.

\subsection{Computer education resource allocation based on particle swarm optimization}

Based on the above survey results and data analysis, the student-teacher ratios of the schools in each county and district were summarized, as shown in Figure 2. It can be seen that there is a big gap in student-teacher ratios among different counties and districts. This uneven allocation problem of educational resources needs to be effectively solved for promoting the balanced development and progress of education quality in this region.

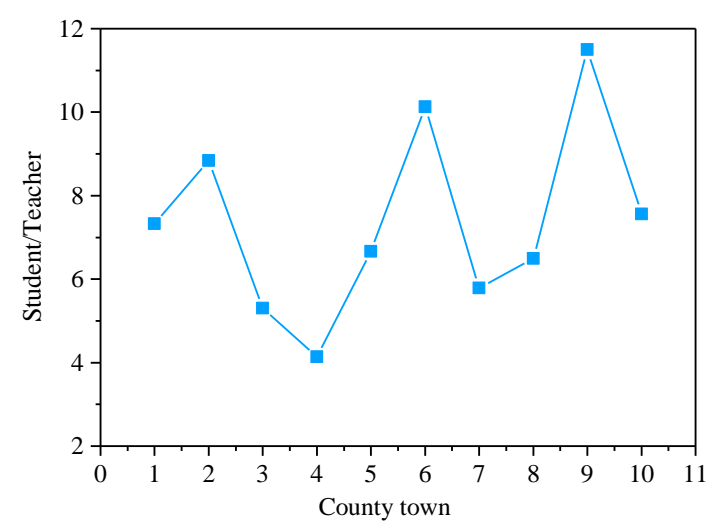

Fig. 2. Student-teacher ratio in different regions

In this study, using the PSO-based allocation model of computer education resource, 1,000 teacher resources newly introduced in the region were allocated to reduce the gap in student-teacher ratio between different counties and districts, coordi- 
nate the rational allocation of educational resources, and narrow the gap in the education quality. The results of the specific allocation are shown in Table 2 and Figure 3.

Table 2. Changes of teacher-student ratio before and after distribution in counties and cities

\begin{tabular}{|c|c|c|c|c|c|}
\hline $\begin{array}{c}\text { Serial } \\
\text { number }\end{array}$ & $\begin{array}{c}\text { Number of } \\
\text { students }\end{array}$ & $\begin{array}{c}\text { Number of } \\
\text { Teachers }\end{array}$ & $\begin{array}{c}\text { Student to } \\
\text { Teacher Ratio }\end{array}$ & $\begin{array}{c}\text { Distribution } \\
\text { number }\end{array}$ & $\begin{array}{c}\text { Teacher-student ratio } \\
\text { after allocation }\end{array}$ \\
\hline 1 & 18231 & 2489 & 7.325 & 0 & 7.325 \\
\hline 2 & 23012 & 2602 & 8.844 & 218 & 8.160 \\
\hline 3 & 6483 & 1223 & 5.301 & 0 & 5.301 \\
\hline 4 & 8827 & 2134 & 4.136 & 0 & 4.136 \\
\hline 5 & 12057 & 1809 & 6.665 & 0 & 6.665 \\
\hline 6 & 16290 & 1608 & 10.131 & 341 & 8.358 \\
\hline 7 & 13921 & 2404 & 5.791 & 0 & 5.791 \\
\hline 8 & 15029 & 2315 & 6.492 & 0 & 6.492 \\
\hline 9 & 13892 & 1208 & 11.500 & 423 & 8.517 \\
\hline 10 & 15932 & 2107 & 7.561 & 18 & 7.497 \\
\hline
\end{tabular}

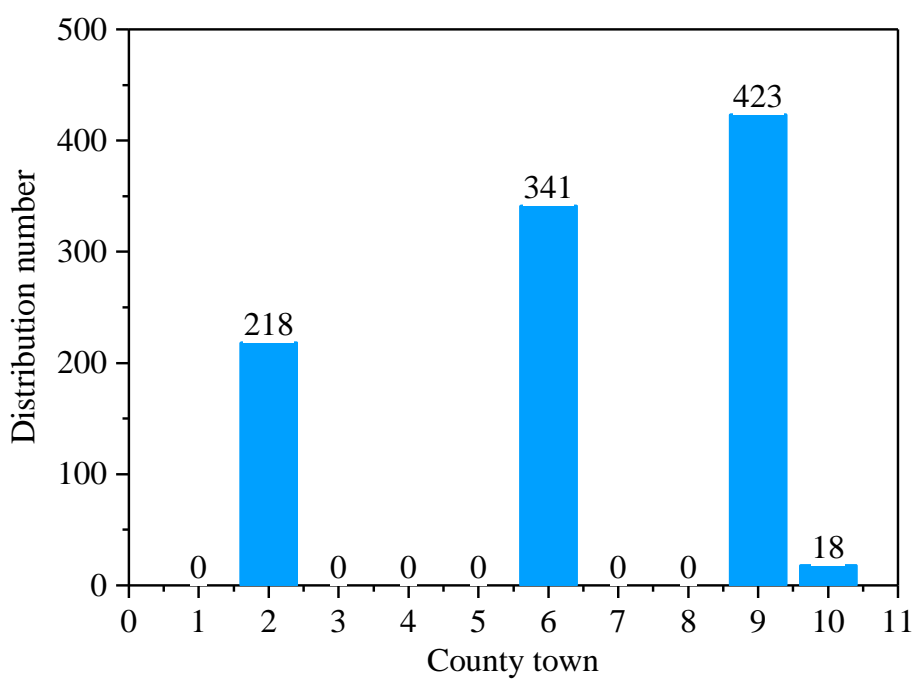

Fig. 3. Distribution of Teachers in Counties and Cities

The allocated results in the above table show that there are 4 districts and counties assigned with new teachers. After the distribution, the ratio of student-teacher decreases significantly. Figure 4 shows the trend chart before and after the distribution, which indicates that through the effective adjustment of the PSO-based allocation model, the imbalance of computer teaching and related educational resources between counties and districts is significantly improved; with the teacher resources continuously adjusted, the resources between the districts and counties can be constantly optimized and balanced, finally achieving the coordinated development of education.

First, the number of computers per capita was calculated for the 1,000 computers, using the particle swarm algorithm, and the related line graph is shown in Figure 5. It 
can be seen that the computer resource allocation is very uneven, and the maximum number is nearly 3 times more than the minimum. Therefore, certain measures should be taken to effectively adjust and allocate computer teaching management resources. For this, the PSO-based teaching resource allocation model was used.

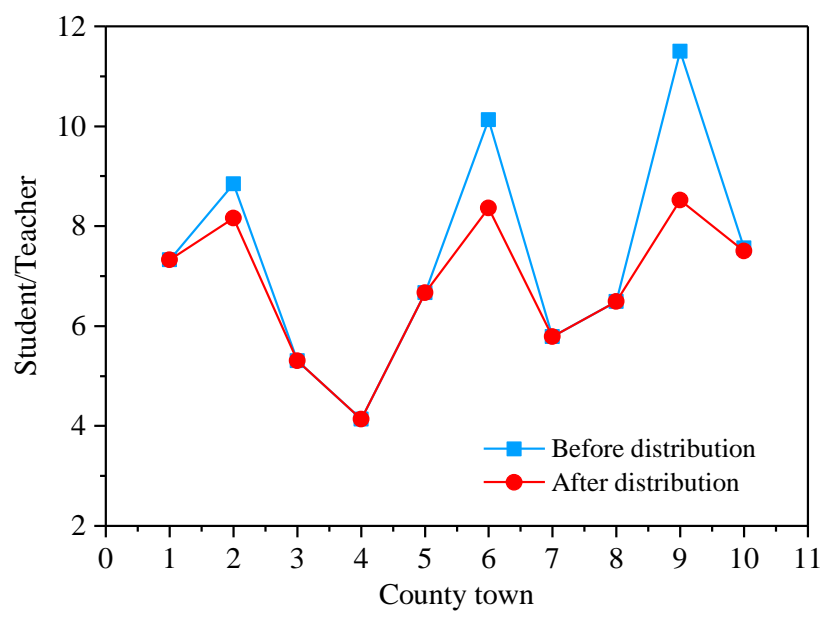

Fig. 4. Comparison of changes in student-teacher ratio before and after allocation

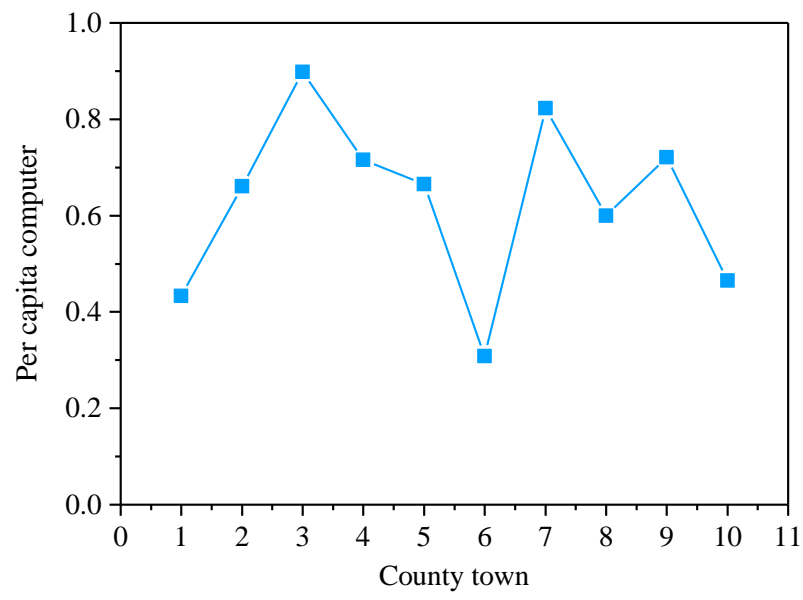

Fig. 5. Per capita computer allocation of counties and cities

1,000 computers were distributed to improve the imbalance in number of computers per capita between different counties and districts, and the distribution calculation results are shown in Table 3 and Figure 6. It can be seen that for counties and districts with a small number of per capita computers, more computers are allocated, thereby 
reducing the gap in the number of computers per capita in schools of each county and balancing the resources of computer teaching management.

Table 3. Changes of per capita computer before and after distribution in counties and municipalities

\begin{tabular}{|c|c|c|c|c|c|}
\hline $\begin{array}{c}\text { Serial } \\
\text { number }\end{array}$ & $\begin{array}{c}\text { Number of } \\
\text { students }\end{array}$ & $\begin{array}{c}\text { Number of } \\
\text { computers }\end{array}$ & $\begin{array}{c}\text { Per capita computer } \\
\text { number before alloca- } \\
\text { tion }\end{array}$ & $\begin{array}{c}\text { Allocate the } \\
\text { number of } \\
\text { computers }\end{array}$ & $\begin{array}{c}\text { computers per } \\
\text { capita after alloca- } \\
\text { tion }\end{array}$ \\
\hline 1 & 18231 & 7891 & 0.433 & 356 & 0.452 \\
\hline 2 & 23012 & 15203 & 0.661 & 0 & 0.661 \\
\hline 3 & 6483 & 5821 & 0.898 & 0 & 0.898 \\
\hline 4 & 8827 & 6321 & 0.716 & 0 & 0.716 \\
\hline 5 & 12057 & 8012 & 0.665 & 0 & 0.665 \\
\hline 6 & 16290 & 5022 & 0.308 & 459 & 0.336 \\
\hline 7 & 13921 & 11456 & 0.823 & 0 & 0.823 \\
\hline 8 & 15029 & 9021 & 0.600 & 0 & 0.600 \\
\hline 9 & 13892 & 10023 & 0.721 & 0 & 0.721 \\
\hline 10 & 15932 & 7405 & 0.465 & 185 & 0.476 \\
\hline
\end{tabular}

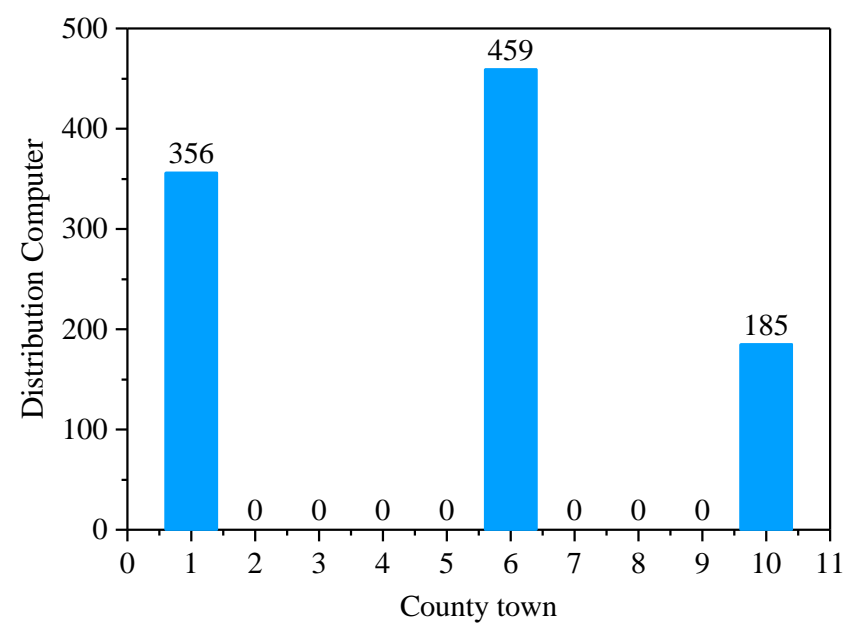

Fig. 6. Computer distribution results of counties and municipalities

After the distribution, there were three counties and districts with lower per capita computers that were allocated with computers, but with insignificant improvement effect. The contrast before and after the distribution is shown in Figure 7. It can be seen from Figure 7 that the counties and districts with a low number of computers per capita were allocated with computers, but there was no obvious increase in the per capita computers after the distribution, and the unbalance in education resource wasn't improved significantly, due to their large student base, and the small number of allocated computers. Therefore, it is necessary to plan resource allocation in advance when carrying out infrastructure construction, rather than making up for it af- 
terwards in order to fundamentally solve the problem of imbalance in educational resources.

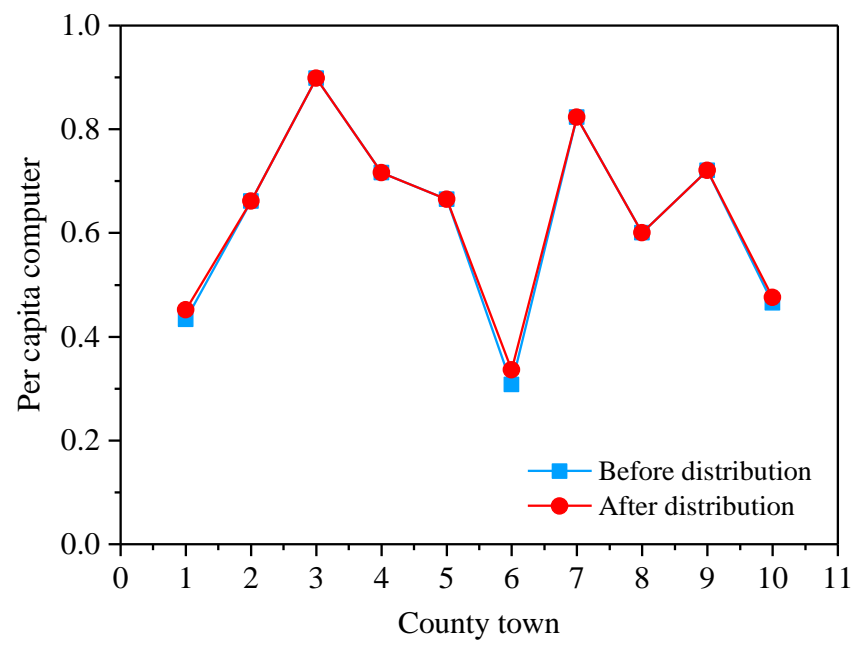

Fig. 7. Comparison of computer distribution in counties and cities

The allocation of educational resources is a very complicated task in itself. It requires governments at the level of district and county, educational institutions and schools to complete this tedious work step by step. To ensure the balance of educational resources as much as possible, big data analysis is needed. In this paper, the POS can provide powerful help for the distribution of computer education resources. Comprehensively considering the educational resources of each county and district, a resource allocation model was established, to improve the imbalance of educational resources, and help the education department make decisions, thereby ensuring the rational allocation of educational resources at the most extent.

\section{Conclusion}

The education of computer and related disciplines are particularly important in today's information age. In view of the uneven allocation and low utilization of computer teaching management resources, this paper establishes an effective allocation model of computer teaching management resources based on the theory of PSO and mathematical statistics, and analyses the distribution of teaching resources in a certain region. The main conclusions are as follows:

- This paper establishes a PSO-based computer teaching management resource allocation model to coordinate the imbalance of existing educational resources, enhance the utilization of educational resources and reduce the waste of some resources; 
- Through the effective adjustment of this allocation model, the imbalance in computer teaching management and related educational resource between different counties and districts have been significantly improved; with the continuous adjustment of teacher resources, the educational resources between all districts and counties will continue to be optimized, ultimately promoting the coordinated development of education;

- Using the effective allocation model of educational resources proposed in this paper, the newly introduced computers are reasonably distributed to schools with a low number of per capita computers according to certain rules, which is conducive to the education reform and progress of schools with relatively few educational resources.

\section{$5 \quad$ References}

[1] Zemach, R. (2007). A state-space model for resource allocation in higher education. IEEE Transactions on Systems Science \& Cybernetics, 4(2): 108-118. https://doi.org/10.1109/ $\underline{\text { tssc. } 1968.300137}$

[2] Cahill C. J. (2006). An efficient resource management system for a streaming media distribution network. Interactive Technology and Smart Education, 3(1): 31-44. https://doi.org/10.1108/17415650680000051

[3] Danthurebandara, V. M., Yu, J., Vandebroek, M. (2011). Sequential choice designs to estimate the heterogeneity distribution of willingness-to-pay. SSRN Electronic Journal, 9(4): 429-448. https://doi.org/10.2139/ssrn.1683900

[4] Dutot, V., Bergeron, F., Raymond, L. (2014). Information management for the internationalization of smes: an exploratory study based on a strategic alignment perspective. International Journal of Information Management, 34(5): 672-681. https://doi.org/10.1016/j.ijin fomgt.2014.06.006

[5] Rumi, Y. F., Prodhan, U. K., Hussain, M. I., Parvez, A. H. M. S., Hossain, M. A. (2013). Strategy for assessment of land and complex fields type analysis through, GIS in Bangladesh. Computer Science, 3(4): 19-31. https://doi.org/10.5121/ijist.2013.3403

[6] Randolph, C., Main, R. (2005). Exploring the power and politics of a peoplesoft implementation, Qualitative Case Studies on Implementation of Enterprise Wide Systems, C hicago, 140-159. https://doi.org/10.4018/978-1-59140-447-7.ch009

[7] Curran, C., Saunders, R. (1992). The use of computer-based systems in the resource management of a developing national distance education programme. Education and Computing, 8(1-2): 33-39. https://doi.org/10.1016/0167-9287(92)80008-y

[8] Hao, O.Y., Lu, X.Y. (2009). On the construction of a human resources management information system based on CSCW for institution of higher education, 2009 International Conference on E-Learning, E-Business, Enterprise Information Systems, and E-Government. https://doi.org/10.1109/eeee.2009.79

[9] Dong, T., Ma, Y., Liu, L. (2012). The application of cloud computing in universities' education information resources management, Lecture Notes in Electrical Engineering, 938945. 154. https://doi.org/10.1007/978-1-4471-2386-6_122

[10] Zhao, G., Ye, Q. X., Chen, L. J. (2013). The research of educational resource management system based on cloud computing. Applied Mechanics and Materials, 380-384: 4695-4699. https://doi.org/10.4028/www.scientific.net/amm.380-384.4695 
[11] Bo, L. (2014). Security problems and strategies of digital education resource management in cloud computing environment, Lecture Notes in Electrical Engineering, 269: 2495-2499. http://dx.doi. org/10.1007/978-94-007-7618-0_310

[12] Koch, F., Assuncao, M. D., Cardonha, C., Netto, M. A. S. (2015). Optimising resource costs of cloud computing for education. Future Generation Computer Systems, 55: 473479. https://doi.org/10.1016/j.future.2015.03.013

[13] Awad, M. (2017). GPMS: an educational supportive graduation project management system. Computer Applications in Engineering Education,25(6): 881-894. https://doi.org/ $\underline{10.1002 / \mathrm{cae} .21841}$

[14] Jackowski, Edward, M. (1988). The next step in educational program budgets and information resource management. Journal of Research on Computing in Education, 21(1): 114. https://doi.org/10.1080/08886504.1988.10781856

[15] Bezerra, H. M. D. A., Karlsson, B., Cabral de Araújo Gois, M., Frery, A.C. (2002). Resource management in computer graphics teaching. Proceedings. XV Brazilian Symposium on Computer Graphics and Image Processing. https://doi.org/10.1109/sibgra. $\underline{2002.1167205}$

[16] Zhang, H., Li, X., Li, H., Huang, F. (2005). Particle swarm optimization-based schemes for resource-constrained project scheduling. Automation in Construction, 14(3): 393-404. https://doi.org/10.1016/j.autcon.2004.08.006

[17] Shou, Y. Y., Li, Y., Lai, C. T. (2015). Hybrid particle swarm optimization for preemptive resource-constrained project scheduling. Neurocomputing, 148: 122-128. https://doi.org/ 10.1016/j.neucom.2012.07.059

[18] Chen, R. M., Wu, C. L., Wang, C. M., Lo, S. T. (2010). Using novel particle swarm optimization scheme to solve resource-constrained scheduling problem in PSPLIB. Expert Systems with Applications, 37(3): 1899-1910. https://doi.org/10.1016/j.eswa.2009.07.024

[19] Soares, J., Sousa, T., Morais, H., Vale, Z., Canizes, B., Silva, A. (2013). Applicationspecific modified particle swarm optimization for energy resource scheduling considering vehicle-to-grid. Applied Soft Computing, 13(11): 4264-4280. https://doi.org/10.1016/ j.asoc.2013.07.003

\section{$6 \quad$ Author}

Xiang Yang, male, was born on March 28, 1982, with a Master's degree,major in Software engineering. He is currently working as an engineer at Nanjing University of Finance and Economics in Nanjing, China. He has been engaged in Network security and information technology in university for more than 10 years. He has published several articles on computer network security and algorithms.

Article submitted 2019-07-03. Resubmitted 2019-08-11. Final acceptance 2019-08-12. Final version published as submitted by the authors. 